\title{
Angiopoietin-1 promotes functional neovascularization that relieves ischemia by improving regional reperfusion in a swine chronic myocardial ischemia model
}

\author{
Winston S.N. Shim ${ }^{1,2, *}$, Wei $\mathrm{Li}^{2}$, Li Zhang ${ }^{2}$, Shiqi $\mathrm{Li}^{1}$, Hwee Choo Ong ${ }^{1}$, In-Chin Song ${ }^{3}$, \\ Akanksha Bapna ${ }^{4}$, Ruowen $\mathrm{Ge}^{4}$, Yean Teng Lim ${ }^{5}$, Seng Chye Chuah ${ }^{6}$, \\ Eugene K.W. Sim $^{2}$ \& Philip Wong ${ }^{6}$ \\ ${ }^{1}$ Research and Development Unit, National Heart Center, 17 Third Hospital Avenue, Singapore, 168752, \\ Singapore; ${ }^{2}$ Department of Surgery, National University of Singapore, 5 Lower Kent Ridge Road, Singapore, \\ 119074, Singapore; ${ }^{3}$ Department of Experimental Surgery, Singapore General Hospital, 17 Third Hospital \\ Avenue, Singapore, 168752, Singapore; ${ }^{4}$ Department of Biological Sciences, National University of Singa- \\ pore, 10 Kent Ridge Crescent, Singapore, 119074, Singapore; ${ }^{5}$ Cardiac Department, National University \\ Hospital, 5 Lower Kent Ridge Road, Singapore, 119074, Singapore; ${ }^{6}$ Department of Cardiology, National \\ Heart Center, 17 Third Hospital Avenue, Singapore, 168752, Singapore
}

Received 28 December 2005; accepted 22 February 2006

(C) 2006 National Science Council, Taipei

Key words: angiogenesis, angiopoietin, ischemia, regional perfuison

\section{Summary}

This study investigates the long-term angiogenic effects of ANG-1 and VEGF in a swine chronic myocardial ischemia model. Four-weeks after gradual occlusion of the left circumflex coronary artery by ameroid constrictor, animals were injected with recombinant adenoviral vectors carrying either human ANG-1 $(n=9)$, human $\operatorname{VEGF}_{165}(n=10)$ or empty vector $(n=7)$ into the left ventricle free wall supplied by the constricted artery. Left ventricular perfusion in animals that received AdANG-1 $(3.25 \pm 0.16 \mathrm{ml} / \mathrm{min} / \mathrm{g}, p<0.05)$ recovered robustly 4 weeks after gene transfer while ischemia persisted in the AdVEGF $(1.09 \pm 0.13 \mathrm{ml} / \mathrm{min} /$ g) and empty vector $(1.20 \pm 0.03 \mathrm{ml} / \mathrm{min} / \mathrm{g})$ groups. Microvascular densities in the left ventricles of animals that received AdANG-1 $\left(19.61 \pm 1.76 / 0.572 \mathrm{~mm}^{2}\right.$ myocardial tissue, $\left.p<0.05\right)$ and AdVEGF $(18.17 \pm 1.43 /$ $0.572 \mathrm{~mm}^{2}$ myocardial tissue, $p<0.05$ ) were significantly higher than animals that received empty vector $\left(13.53 \pm 0.92 / 0.572 \mathrm{~mm}^{2}\right.$ myocardial tissue) 12 weeks after gene transfer. ANG-1, but not VEGF, contributed to enhanced regional perfusion by increasing arteriolar density $\left(1.9 \pm 0.4 / 0.572 \mathrm{~mm}^{2}\right.$ myocardial tissue vs. $0.7 \pm 0.2 / 0.572 \mathrm{~mm}^{2}$ myocardial tissue, $\left.p<0.05\right)$ of large-sized $(50-100 \mu \mathrm{m})$ arterioles. These data demonstrate that gene transfer of ANG-1 and VEGF enhances angiogenesis, but ANG-1 promotes sustained improvement of ventricular perfusion that expedites recovery of ischemic myocardium via arteriogenesis.

\section{Introduction}

Ischemic heart disease is a leading public health concern in the developed world. Despite maximal therapy, a proportion of patients with symptoms

*To whom correspondence should be addressed. Fax: +656224-1107; E-mail: winston_shim_sn@nhc.com.sg of chronic ischemia are refractory to conventional drug treatments or revascularization techniques. Some patients are not amenable to percutaneous coronary intervention or coronary artery bypass grafting surgery due to the severe diffused nature of the disease. The symptoms of angina may be debilitating and severely impair quality of life. 
Revascularization through therapeutic angiogenesis has the potential to complement conventional revascularization techniques and may extend treatment options to patients who fail conventional methods of myocardial revascularization. Successful therapeutic angiogenesis has been reported with vascular endothelial growth factor (VEGF) and fibroblast growth factor (FGF) in ischemic animal models [1, 2]. Early clinical trials in a small number of myocardial ischemic patients have been encouraging [3-6]. However, recent phase II controlled trials using VEGF and FGF-2 demonstrated only minimal clinical benefits with no improvement in myocardial perfusion at follow-up [7,8]. These results indicate that myocardial angiogenesis in ischemic heart may be more complicated than previously believed and its long-term benefits remain uncertain. Alternative growth factors that target different aspects of vascular development may be needed to enhance therapeutic outcomes of angiogenesis in chronic ischemia.

Due to their anatomical similarities to the human cardiovascular system, experiments on large animal models are warranted to better understand the mechanisms underlying new blood vessel formation in ischemic myocardium. Swine are preferred because they have fewer pre-existing collaterals in the coronary system [9]. Chronic myocardial ischemia can be achieved by surgical implantation and intermittent inflation of an external pneumatic coronary occluder [2, 10], or by placing an ameroid constrictor around a major coronary artery, usually the proximal left circumflex [1, 11-14]. Ameroid constrictor has been most widely used to study chronic myocardial ischemia in porcine model $[15,16]$. The constrictor consists of encased hygroscopic casein that expands when in contact with fluid, resulting in a gradual occlusion of the encircled artery. Experimental protocols typically involve administration of growth factors 3-4 weeks after implantation of the constrictor, by which time the casein compressed artery has rendered the myocardium ischemic. Progressive occlusion is preferred because of the associated low incidence of major infarction [14].

Angiopoietin-1 (ANG-1) was first identified as an agonist ligand for endothelial-specific TIE-2 tyrosine receptor kinase [17] and followed by other members of the human angiopoietin family,
ANG-2 and ANG-4 [18]. Despite being poorly mitogenic, ANG-1 shares some of the pro-angiogenic characteristics of VEGF. Both factors induce endothelial sprouting and promote survival of endothelial cells $[19,20]$. Although VEGF has been considered one of the most potent angiogenic factors in the early stages of angiogenesis, there is increasing evidence suggesting ANG-1 also plays a critical role in early phase angiogenesis [21, 22]. ANG-1, by mediating interaction between endothelial cells and their underlying supporting cells, has been shown to promote angiogenesis in synergy with VEGF to form mature vasculature [22, 23]. This interaction may also act to maintain stability and integrity of the vasculature over a longer term [24]. Furthermore, ANG-1 is the first growth factor identified to exhibit a potent anti-permeability effect on blood vessels. This occurs even in the presence of strong permeability-inducing factors, such as VEGF and other inflammatory molecules $[25,26]$. It regulates vascular permeability by modulating junctional complexes between endothelial cells [25] thereby maintaining vascular integrity. This may in turn improve blood flow dynamics via normalization of the microcirculation $[27,28]$.

Importance of ANG-1 in embryonic heart development has been well documented [24]. However, the effect of ANG-1 on the revascularization of ischemic myocardium remains poorly understood. Detailed characterization will aid in the understanding of subtle and unique roles of individual angiogenic factors in forming functional vasculature during myocardial ischemia. In this study, we investigate if adenoviral-mediated gene transfer of ANG-1 and VEGF is effective in stimulating sustained neovascularization by studying their long-term effects on vascular development and myocardial perfusion in a swine chronic ischemia model.

\section{Methods}

Replicative-deficient adenoviral vector construction

The replicative-deficient vector AdANG-1, AdVEGF and empty vector were constructed using an E1/E3-deleted adenovirus serotype 5 vector from Microbix Biosystems Inc (Toronto, Ontario, Canada). The transgene (no transgene for empty 
vector construct) is driven by a human cytomegalovirus immediate early promoter/enhancer. The vectors were propagated and purified in human embryonic kidney-293 cells as described [29]. Before use, concentration of viral particles in the stock was determined at $260 \mathrm{~nm}$ using a spectrophotometer and infectious titer (PFU, plaque-forming unit) determined using the limiting dilution method in 293 cells as described [29]. All vectors used were within particle to infectious titer ratio of below 100 . The potency and functionality of our expressed recombinant human $\mathrm{ANG}-1$ and $\mathrm{VEGF}_{165}$ proteins on receptor binding and endothelial cell proliferation have been described previously [29-31].

\section{Porcine model of chronic myocardial ischemia and gene transfer using AdANG-1 and AdVEGF}

All experimental animals were cared for in accordance with guidelines outlined by institutional animal care and use committee (IACUC). Yorkshire swine $(30-35 \mathrm{~kg})$ were tranquilized with ketamine $(20 \mathrm{mg} / \mathrm{kg})$ and atropine sulphate $(0.05 \mathrm{mg} / \mathrm{kg})$, inducted with thiopentone (up to $20 \mathrm{mg} / \mathrm{kg}$ or until sufficient relaxation), intubated and maintained with general inhalation anesthesia with $2 \%$ isofluorane. Cefazolin $(40 \mathrm{mg} / \mathrm{kg})$ and Labetalol $(1 \mathrm{mg} / \mathrm{kg})$ were given intravenously as prophylaxis against wound infection and arrhythmia. Buprenorphine (up to $0.1 \mathrm{mg} / \mathrm{kg}$ as hydrochloride) was given for analgesia. A left anterior mini-thoracotomy was performed through the fourth intercostal space and the pericardium was incised and suspended to reveal the free wall of the left ventricle. Ameroid constrictor (Research Instruments SW, Escondido, CA, USA) with 2.0-2.5 mm internal diameter was placed around the circumflex artery ( $\mathrm{LCx}$ ) as proximally as possible. Four weeks after placement of ameroid constrictor, a second left thoracotomy was performed and a total of 26 pigs were randomized into three treatment groups. The animals received 10 intramyocardial injections (100 ul per injection) totaling $1 \times 10^{10}$ plaque forming unit (PFU) of recombinant adenoviral vector carrying human ANG-1 $(n=9)$, human VEGF $(n=10)$ or empty vector $(n=7)$. The respective vectors were injected using a 27-gauge needle into the free wall of LCX territory under direct vision with depth limited to 3-4 $\mathrm{mm}$ and the sites suture marked for identifica- tion. The pericardium and chest were closed, moisture vapor spray dressing and topical antibiotic powder were applied to the incision, and the animals were allowed to recover. Healthy nonischemic animals $(n=6)$ that did not receive ameroid constrictors were left untreated as baseline controls.

\section{Regional blood flow measurement}

Four weeks after placement of ameroid constrictors, fluorescent microspheres purchased from Molecular Probes (Eugene, OR, USA) were administered shortly before vector delivery. Microspheres administration was repeated at 4 and 12 weeks after gene delivery. Microspheres with 15 um diameter in three distinct spectral range; yellow-green [cat. no. F-8844], red [cat. no. F-8842] and scarlet [cat. no. F-8843], were injected at $2.5 \times 10^{5}$ microspheres $/ \mathrm{kg}$ body weight at each time point. At least five transmural myocardial tissues around the suture marked sites in the free wall were digested to recover trapped microspheres. Fluorimetry was performed on the extracted fluorescent dyes using a Perkin-Elmer LS-50B spectrofluorometer (Boston, MA, USA). All studied animals were included for analysis and all samples were processed with identical parameter settings and blood flow rate $(\mathrm{ml} / \mathrm{min} / \mathrm{g})$ was determined as described by manufacturer.

\section{Coronary angiography}

Coronary angiography was performed on representative animals $(n=3-4)$ from each experimental group to confirm occlusion of the left circumflex artery at the end of experiment. A 6-French Judkins left end-hole diagnostic catheter was placed in the left main coronary artery. The contrast medium was injected at a continuous rate until the entire left coronary system and its branches were completely opacified. Cinefluoroscopy was performed in standard right anterior oblique projection with continuous image acquisition. Collateral vessels from the left anterior descending coronary artery or obtuse marginal branch of the circumflex coronary artery, were quantified following the grading method described previously [32] by an interventional cardiologist that was blinded to the study. 


\section{Immunohistological analysis}

Animals were sacrificed 12 weeks after treatment and the hearts were perfusion fixed with ice-cold $4 \%$ formaldehyde. Transmural myocardial tissue blocks of $3 \mathrm{~cm} \times 1 \mathrm{~cm}$ covering the epicardium to endocardium were taken from the anterior and lateral walls of left ventricle. Paraffin sections of $5 \mu \mathrm{m}$ were prepared for immunohistochemical staining. Sections were digested with $0.05 \%$ protease (Sigma-Aldrich, St. Louis, MO, USA), quenched with $3 \%$ hydrogen peroxide and blocked in 5\% goat serum and stained using anti-von Willebrand factor (vWF) antibody (DakoCytomation, Glostrup, Denmark) and anti-smooth muscle actin (SMA) antibody (clone 1A4, Sigma) for endothelial and smooth muscle cells, respectively, and anti-human ANG-1 (USBiological, Swampscott, USA) or anti-human VEGF (NeoMarkers, Fremont, USA) for overnight at $4{ }^{\circ} \mathrm{C}$. This was followed by incubating the sections with peroxidase-labeled polymer (Dakocytomation) and signals developed with diaminobenzidine (DAB) substrate, counterstained with hematoxylin and mounted in Canadian Balsam.

\section{Morphometric analysis and microvascular density determination}

The extent of neoangiogenesis was quantified 12 weeks after gene transfer by measuring vascular density of vWF-stained blood vessels in the ischemic myocardium. Microvessels with a clearly identifiable lumen with diameter less than $20 \mu \mathrm{m}$ that oriented perpendicular were counted as positively stained vessels [33]. This lumen size was selected based on findings that these microvessels were most responsive to ANG-1 and VEGF stimulation [34]. Arterioles that stained positive for $\alpha$-smooth muscle actin were analyzed and categorized based on lumen diameter (LD) into small $(20 \mu \mathrm{m}>\mathrm{LD}<50 \mu \mathrm{m})$-and large-sized arterioles $(50 \mu \mathrm{m}>\mathrm{LD}<100 \mu \mathrm{m})$. Average microvessel area $\left(\mu \mathrm{m}^{2} /\right.$ vessel $/ 0.572 \mathrm{~mm}^{2}$ myocardial tissue) was determined from SMA-stained microvessels by outlining the smooth muscle layer that surrounding a visible vessel lumen of less than $100 \mu \mathrm{m}$ in diameter. Counting of all vessels was restricted to the myocardium and vessels in the connective tissues near the pericardium were excluded.
Microscopic images (XY resolution of $1300 \times 1030$ pixels with calibrated scaling of $0.6536 \mu \mathrm{m} /$ pixel corresponding to a viewing field of $0.572 \mathrm{~mm}^{2}$ myocardial tissue) were acquired with a $10 \times \mathrm{A}$ Plan objective lens $(\mathrm{NA}=0.25)$ using a Zeiss Axiovert $200 \mathrm{M}$ microscope and morphometric data were analyzed using AxioVision 4.3 software (Carl Zeiss, Hellbergmoos, Germany). Tissue sections from all studied animals were sampled for analysis and random microscopic fields (0.572 $\mathrm{mm}^{2}$ myocardial tissue/microscopic field) were examined. The mean number of vWF or SMA stained vessels from each experimental group was calculated by averaging the total number of vessels counted from all the sampled tissues.

\section{Gene expression by $R T-P C R$}

In an independent experiment from the main study, temporal expression profile of human ANG-1 and human VEGF was separately examined by RT-PCR following vector-administration into pigs $(n=3)$ with myocardial ischemia. The viral vectors carrying these genes were introduced into the ischemic ventricular free wall after creation of the ischemic model as described in the main study. The animals were sacrificed 1, 3 and 4 weeks following gene transfer. Transmural myocardial samples from vector-treated ischemic area and right ventricle (as control) of each pig were excised and cleaned of fatty tissues in ice-cold PBS. RNA was isolated from cardiac tissue using TRI Reagent $^{\circledR}$ (Molecular Research Center Inc, Cincinnati, OH, USA) as described. RT-PCR was performed using Qiagen Onestep RT-PCR Kit (Valencia, CA, USA) and products amplified at $94{ }^{\circ} \mathrm{C}, 30 \mathrm{~s}, 57^{\circ} \mathrm{C}, 60 \mathrm{~s} 72^{\circ} \mathrm{C}, 60 \mathrm{~s}$ for 35 cycles. A combination of gene-specific (5'-CGGTGAA TATTGGCTGGGGAATGAG-3') and vectorspecific primers (5'-CCATTATAAGCTGCAA TAAACAAG-3') was used to detect ANG-1 expression. Vector-specific primers (5'-GATCCAG CCTGGGGATCAGTCTTCG-3' and 5'-CCAT TATAAGCTGCAATAAACAAG-3') were used to detect the human VEGF message.

\section{Statistical analysis}

Differences among treatments were analyzed with one-way analysis of variance (ANOVA) and 
Tukey test was carried out for subsequent post-hoc pairwise comparisons. Results were reported as mean \pm standard error of mean (SE). All statistical tests were performed at the $p<0.05$ significance level using SPSS statistical analysis software version 11 (SPSS Inc, Chicago, IL, USA).

\section{Results}

Chronic ischemia with total occlusion of left circumflex artery

Angiography confirmed complete occlusion of the circumflex coronary artery of all animals examined 16 weeks post placement of constrictor (Figure 1). Collaterals were observed in all the hearts examined regardless of the treatment received. However, the size of the vessels formed after gene transfer was too small to permit meaningful angiographic determination.

Viral-mediated gene transfer evokes minimal inflammation in the injected tissues

Fibrotic tissues were mainly observed in areas surrounding the occluded left circumflex artery that were in close proximity to the ameroid constrictor. There were no infarct scars nor any active inflammation in the injected myocardium of animals that received AdANG-1, AdVEGF or empty vector (data not shown).
$A N G-1$, but not VEGF, enhances regional blood flow in the ischemic myocardium

Animals developed ischemia 4 weeks after arterial constriction with pre-treatment regional blood flow (RBF) at rest (mean $\pm \mathrm{SE}, \mathrm{ml} / \mathrm{min} / \mathrm{g}$ ) significantly reduced in animals randomized to receive either AdANG-1 $(1.14 \pm 0.10, p<0.005)$, AdVEGF $(1.01 \pm 0.08, p<0.001)$ or empty vector $(1.05 \pm 0.04, p<0.001)$ compared to healthy nonischemic (1.56 \pm 0.07$)$ animals. The RBF among the treatment groups was not significantly different $(p=0.338)$ before initiation of respective treatment regimes (Figure 2).

Myocardial perfusion in AdANG-1 group improved by 4 weeks with left ventricular RBF $(3.25 \pm 0.16, p<0.001)$ recovering significantly compared to healthy non-ischemic animals $(1.56 \pm 0.07)$ in a robust angiogenic response. This angiogenic effect of ANG-1 was sustained with RBF levels remaining elevated at 12 weeks $(2.77 \pm 0.28, p<0.05)$ after gene transfer (Figure 3). In contrast, ischemia persisted in AdVEGF $(1.09 \pm 0.13, p<0.05)$ and empty vector $(1.20 \pm 0.03, p<0.05)$ groups at 4 weeks after treatments. The RBF rates in both groups returned to levels comparable to healthy non-ischemic animals by 12 weeks after therapy.

Regional blood flow rates in animals that received AdVEGF were statistically insignificant compared to those that received empty vector at $4(1.09 \pm 0.13$ vs. $1.20 \pm 0.03, p=0.905)$ and 12 $(1.86 \pm 0.69$ vs. $1.32 \pm 0.04, \quad p=0.715) \quad$ weeks after gene delivery. In contrast, ANG-1 therapy

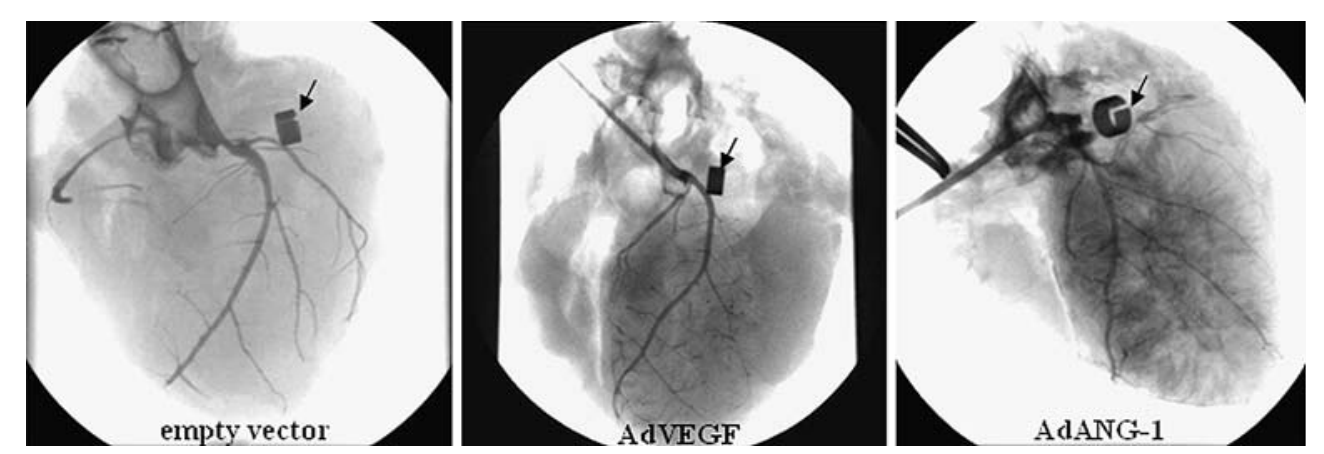

Figure 1. Coronary angiography of ischemic swine showed complete occlusion of the left circumflex artery 16 weeks after placement of ameroid constrictor. Collaterals were detectable in all groups regardless of treatment received. Arrows indicated ameroid constrictors. 


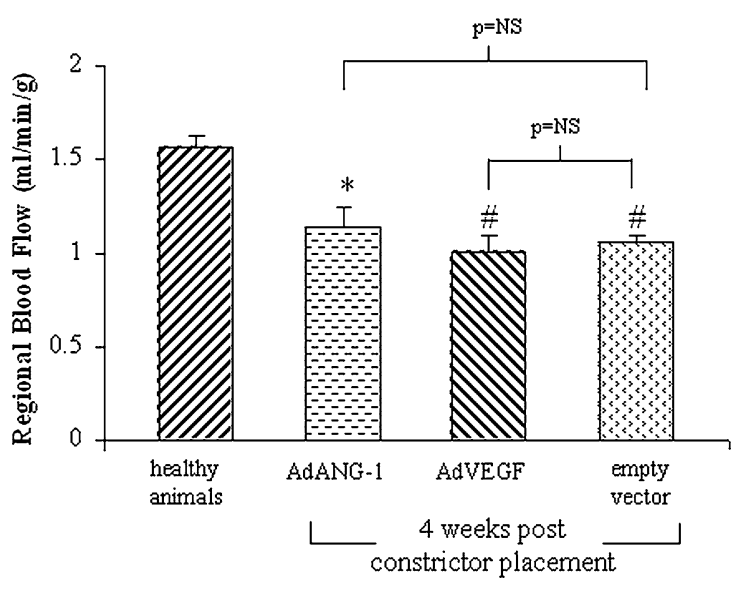

Figure 2. Animals developed ischemia 4 weeks after arterial constriction with ameroid constrictor. There was no significant difference in the depressed regional perfusion among animal groups before initiation of treatment. ${ }^{*} p<0.005$ vs. healthy control animals, $\# p<0.001$ vs. healthy control animals.

significantly improved myocardial perfusion compared to animals that received empty vector at 4 $(p<0.001)$ and $12(p<0.05)$ weeks after therapy (Figure 3).

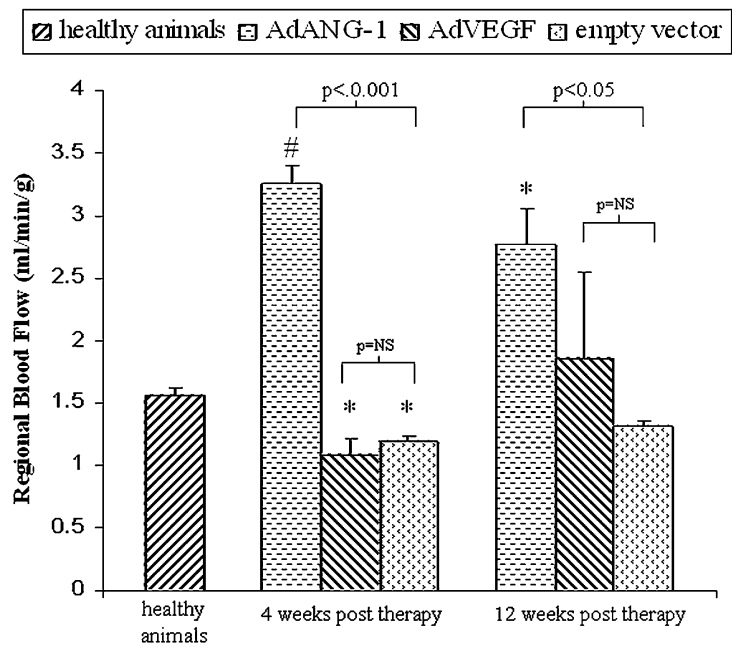

Figure 3. ANG-1 therapy rescued animals from ischemia with robust recovery in left ventricular perfusion compared to AdVEGF and empty vector treated groups. The therapeutic effect of ANG-1 was sustainable with continuous elevated ventricular perfusion in the left circumflex territory. ${ }^{*} p<0.05$ vs. healthy control animals, $\# p<0.001$ vs. healthy control animals.
ANG-1 promotes angiogenesis and enhances arteriole formation in the ischemic myocardium

Immunohistological analysis of the paraffin sections with anti-von Willebrand factor (vWF) and anti-smooth muscle actin (SMA) antibodies revealed neither grossly abnormal vessels nor any hemangioma-like structures in the tissues examined. Majority of the vasculature were made up of vessels with diameter less than $20 \mu \mathrm{m}$ (Figure 4A). Left ventricular microvascular densities (vessel/ $0.572 \mathrm{~mm}^{2}$ myocardial tissue) based on vWF staining in animals that received AdANG-1 $(19.61 \pm 1.76, p<0.05)$ and AdVEGF $(18.17 \pm$ $1.43, p<0.05)$ were significantly higher than animals that received empty vector $(13.53 \pm 0.92)$ or in healthy control animals $(12.20 \pm 1.03)$ (Figure 4B).

There was no significant difference in the number (arteriole $/ 0.572 \mathrm{~mm}^{2}$ myocardial tissue) of small-sized arterioles (20-50 $\mu$ m diameter) among all the treatment groups. However, a significant increase in the number of large-sized arterioles (50$100 \mu \mathrm{m}$ diameter) was found in the AdANG-1 $(1.9 \pm 0.4, \quad p<0.05)$, but not the AdVEGF $(0.7 \pm 0.2, p=0.892)$, treated myocardium compared to empty vector or healthy control group (Figure 5A and B). In addition, average microvessel area $\left(\mu \mathrm{m}^{2} /\right.$ vessel $/ 0.572 \mathrm{~mm}^{2}$ myocardial tissue) was increased in the AdANG-1 (329.25 \pm 19.56 , $p<0.001$ ) treated myocardium, but not the AdVEGF group (183.97 \pm 11.73$)$, when compared to empty vector $(195.01 \pm 14.09)$ or healthy control $(167.18 \pm 13.25)$ group (Figure 5C).

Expression of human-specific ANG-1 mRNA and VEGF mRNA was detected in the left ventricle at 1 and 3 weeks, but not 4 weeks, after gene delivery (Figure 6). No expression was detected in the right ventricle at the corresponding periods. This was confirmed by immunohistological staining for ANG-1 and VEGF at 3 weeks after treatment (Figure 7). The expression of VEGF and ANG-1 was detected in a punctuated pattern in the myocardium that was consistent with localized injections of the respective recombinant vectors.

\section{Discussion}

Angiogenic growth factors act by inducing proliferation and migration of endothelial cells during 

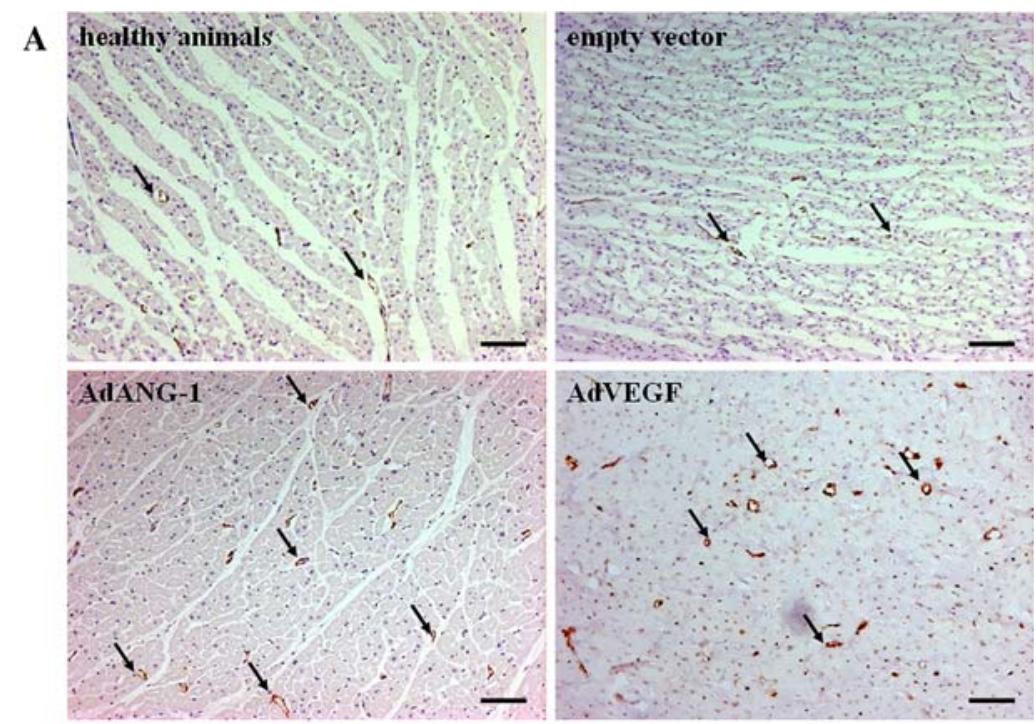

\section{B}

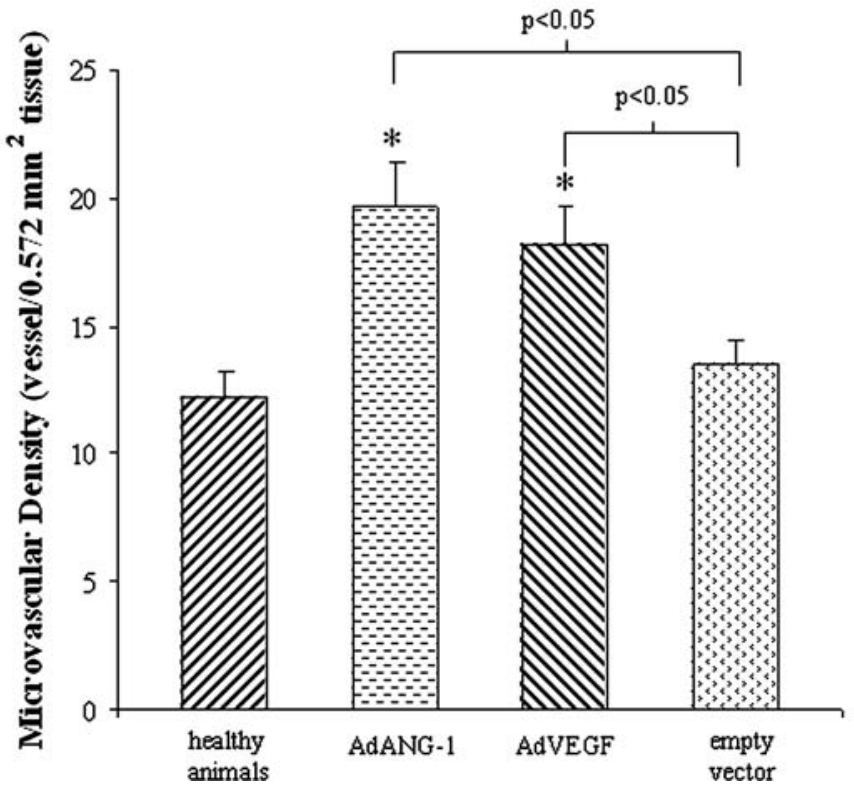

Figure 4. ANG-1 and VEGF augmented vascular angiogenesis in the ischemic myocardium. (A) AdANG-1 and AdVEGF treated myocardium showed enhanced neovascularization with increase von Willebrand factor positive vessels. Arrows indicate positively stained microvessels. Scale bar: $100 \mu \mathrm{m}$. (B) ANG-1 and VEGF significantly increased microvascular density in the left ventricle free wall. Microvascular density was computed based on microvessels with lumen sizes less than $20 \mu \mathrm{m}$. ${ }^{*} p<0.01$ vs. healthy control animals.

angiogenesis. There is evidence to suggest that specific functions unique to individual angiogenic factors may exist during distinct phases of angiogenesis. For example, VEGF has been recognized as a primary initiator of new capillary growth while FGF was implicated in the formation of large collaterals or arteriogenesis in later stages of angiogenesis [35-37]. It is apparent that establish- ing a fully functional neovasculature is likely to require temporal and sequential interaction of several major angiogenic factors in a sustained and coordinated manner.

The precise onset of angiogenesis during ischemia is unknown. However, endothelial proliferation has been observed as soon as 1 day after the onset of coronary microembolization in a porcine 

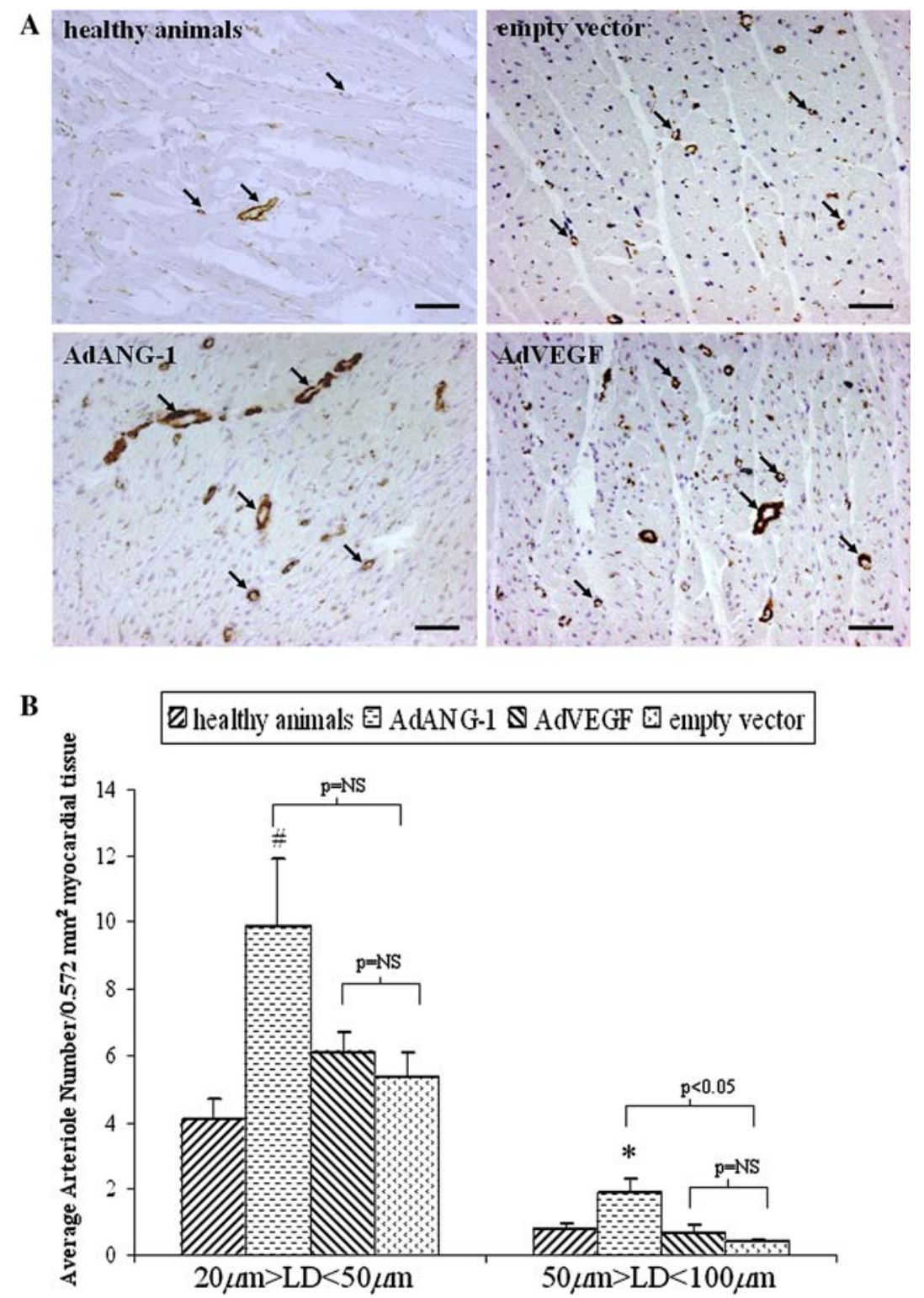

Figure 5. Neovascularization in AdANG-1 treated myocardium was sustained by arteriole formation and vessel expansion. (A) AdANG-1 promoted arteriogenesis in the ischemic myocardium. Arrows indicate alpha-smooth muscle actin positive arterioles. Scale bar: $50 \mu \mathrm{m}$. (B) ANG-1 promoted large-sized arterioles formation that supported stability and integrity of the vasculature. ${ }^{*} p<0.05$ vs. healthy control animals, $\# p<0.005$ vs. healthy control animals. LD: Lumen diameter. (C) ANG-1 significantly augmented average microvessel area in the ischemic myocardium. $\# p<0.001$ vs. healthy control animals.

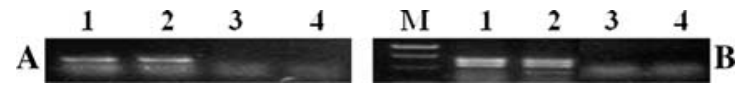

Figure 6. Transient expression of the exogenous human ANG-1 and VEGF mRNA was sufficient to support angiogenesis in the ischemic myocardium. (A) ANG-1, (B) VEGF. Lanes 1-3 represents gene expression 1, 3, and 4 weeks after gene transfer into the left ventricle. Lane 4 represents control samples from right ventricle. M: Molecular marker. model [38]. One-week after the beginning of embolization, capillary growth was mainly in the form of elongation and thickening of the previously existing vessels. In the case of the chronic ischemic model adopted in this study, the pattern of capillary growth may be different from that of an embolism since the process is gradual and the coronary artery is not totally occluded until 


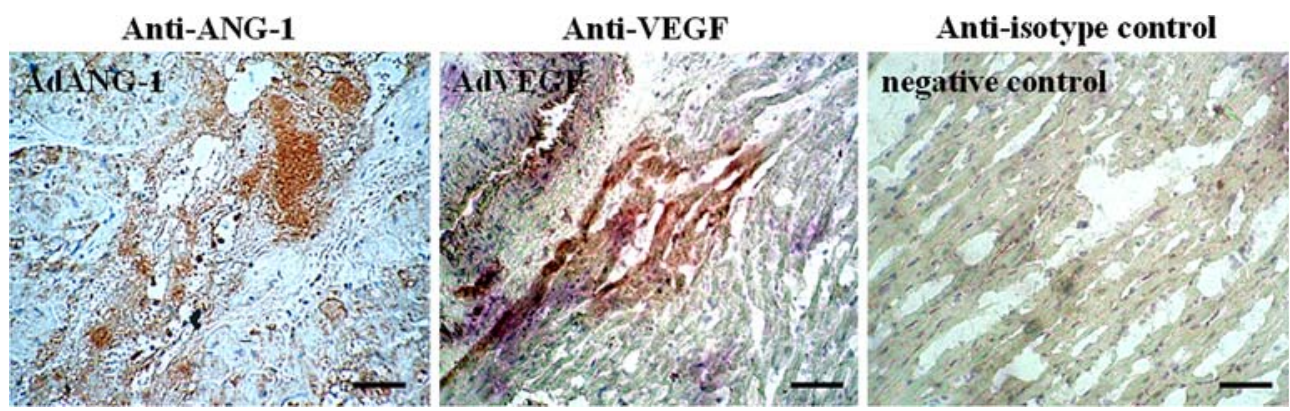

Figure 7. Immunohistochemical staining of ANG-1 and VEGF expression in the myocardium 3 weeks following intramyocardial gene transfer. The punctuated positive brown staining pattern is consistent with localized gene expression. Scale bar: $25 \mu \mathrm{m}$.

3-4 weeks after constrictor placement [39]. There may be an attenuated, but sustained low level angiogenic response during the progressive development of ischemia. Expression of VEGF and its receptors in chronic ischemia is upregulated for at least 2 weeks, suggesting VEGF/VEGFR system acts as a major mediator of ischemic myocardial angiogenesis [33]. Therefore, additional administration of appropriate therapeutic agents in this period is expected to enhance the ongoing angiogenesis. This is especially relevant since native ANG-1 expression is scarce in ischemic myocardium [33, 40], gene transfer of ANG-1 during progressive ischemia period may prove to be useful. This was demonstrated by significant increased microvascular density in the ischemic myocardium of the AdANG-1 group in our study. The comparable vascular density improvement between AdANG-1 and AdVEGF groups supports ANG-1's potency in inducing angiogenesis (Figure 4B). Furthermore, the effect of our AdANG-1 treatment was comparable to the combined therapeutic effect of AdVEGF and skeletal myoblast transplantation on vascular density enhancement that resulted in improved ventricular function in a swine infarction model [41].

ANG-1 has been reported to significantly increase arteriolar density and reduce infarct size leading to improved cardiac performance following AMI in rodent models [42, 43]. Furthermore, ANG-1 has been suggested to enhance hemodynamics by forming more complex vascular network characterized by mature vessels of increased luminal size [44, 45]. Consistently, our study showed ANG-1 augmented microvascular density with significant formation of large-sized arterioles $(50-100 \mu \mathrm{m})$ and increased total microvascular area in the ischemic myocardium (Figure 5B and C).
Animals that received AdANG-1 recovered from ischemia soon after gene transfer with a robust angiogenic response that led to enhanced tissue perfusion, and the effect was sustained for at least 12 weeks following therapy. This is likely the resultant effect of larger size arterioles formed in response to ANG-1's stabilizing or maturating effect since the smaller size arterioles were insufficient to improve tissue perfusion in the AdVEGF or empty vector group (Figure 5B). Furthermore, intense angiogenic response following ANG-1 administration has been reported in an AMI model whereby vascular density in treated rats was more than $60 \%$ higher than control animals [42]. Such robust angiogenic response may be due in part to augmented angiogenesis contributed by circulating vascular progenitor cells since mobilization of endothelial progenitor cells and bone marrow stem cells has been observed in response to ANG-1 [46].

The reduced RBF levels by 12 weeks may indicate a homeostatic response of the heart to continuous elevated blood flow rates induced early after ANG-1 gene transfer. Our previous studies showed functional improvement without any deleterious effects despite transient supraphysiological $\mathrm{RBF}$ rates following therapy in a similar swine model [41]. However, dose-escalating AdANG-1 therapy for a more optimum physiological response may need to be addressed by additional studies.

Despite the importance of VEGF in angiogenesis, our model showed minimal perfusion restoration in response to VEGF. There was no significant difference in the RBF rates between AdVEGF and empty vector groups at both periods examined, even though their RBF levels normalized by the end of the experiment. The 
bioactivity of our vector produced VEGF has been previously demonstrated [30, 31]. This indicates that exogenous VEGF failed to improve ventricular perfusion after gene transfer and it contributed minimally to the normalizing RBF levels observed at the end of the experiment. In contrast to recovery observed in the AdANG-1 group, AdVEGF administered animals remained ischemic at 4 weeks after gene transfer (Figure 3). The recovery of $\mathrm{RBF}$ in AdVEGF group to levels comparable to those of the healthy control animals 12 weeks after gene transfer may be due to native collateral compensation following prolonged ischemia. However, such compensation may not necessary result in recovery of myocardial function as collateral flow is rarely adequate in compensating fully for the flow lost to occlusion of the native epicardial coronary arteries [15, 47].

It is noteworthy that Schwarz et al. [48] failed to observe significant changes in regional blood flow rates despite increased in vascularity in the infarcted rodent myocardium following VEGF administration. Similar findings on VEGF were also reported in canine myocardial ischemic model and rodent hindlimb ischemic model $[49,50]$. It is probable that nascent vessels induced by VEGF alone may function sub-optimally due to insufficient vascular expansion and large arteriole formation as demonstrated by our study (Figure 5B and C). Alternatively, the augmented VEGF levels soon after gene transfer may have increased vascular permeability, leading to tissue edema that impaired tissue perfusion despite comparable increased in microvascular density between AdVEGF and AdANG-1 groups. In fact, ANG-1 has been known to potentiate the angiogenic response to VEGF [45, 51] while counteracting its effect on vascular permeability [25]. Furthermore, ANG-1 was found to enhance perfusion only in the presence of increased levels of endogenous VEGF while exogenous applied VEGF failed to improve collateral blood flow in the ischemic hypoperfused tissues [52]. Therefore, vascular characteristics evoked in response to specific growth factors may explain the discrepancy observed between perfusion and vascularity in our VEGF administered group.

Despite transient gene expression, temporal expression profile of the exogenous ANG-1 and VEGF in our study was adequate to amplify the downstream angiogenic cascade as evidence by the enhanced angiogenesis and augmented arteriole formation in the myocardium. Controlled expression of angiogenic growth factors during angiogenesis is crucial since vasculature induced by prolonged and uncoordinated VEGF expression has been found to form hemangiomas that failed to connect to existing circulation $[48,53,54]$. No abnormal vascular structures were detected in both AdANG-1 and AdVEGF administered groups in our study. This suggests that blood vessels formed soon after gene transfer were stable and functional outcome of the angiogenic response, particularly in the AdANG-1 group, was sustainable for at least 12 weeks despite transient nature of the gene expression.

There was no obvious inflammatory response in the myocardium 12 weeks after gene transfer. However, the slight improvement in vascularity in the empty vector group compared to the healthy animal group suggested that inflammation-led neovascularization might have occurred early following vector administration. Furthermore, effect of surgical related trauma and associated inflammation on angiogenesis cannot be excluded totally.

This study presents for the first time a long-term comparison between ANG-1 and VEGF on the efficacy of therapeutic angiogenesis in a porcine model of chronic myocardial ischemia. Our results provide both anatomical and functional evidence of augmented neovascularization that support ANG-1 as a potent angiogenic and arteriogenic inducer in ischemic myocardium. Importantly, ANG-1, but not VEGF, augmented neovascularization translated to enhanced perfusion and ischemic recovery. The significant improvement in myocardial perfusion supported by ANG-1 provides strong evidence of its functionality during ischemic neovascularization. Its superiority over VEGF in promoting long-term functional neovascularization may have clinical significance in patients with severe chronic ischemia.

\section{Acknowledgement}

This work was supported by the National Medical Research Council of Singapore grant NMRC0730/2003.

\section{References}

1. Crottogini A., Meckert P.C., Vera Janavel G., Lascano E., Negroni J., Del Valle H., Dulbecco E., Werba P., Cuniberti 
L., Martinez V., de Lorenzi A., Telayna J., Mele A., Fernandez J.L., Marangunich L., Criscuolo M., Capogrossi M.C. and Laguens R., Arteriogenesis induced by intramyocardial vascular endothelial growth factor 165 gene transfer in chronically ischemic pigs. Hum. Gene Ther. 14: 1307-1318, 2003.

2. Hughes G.C., Biswas S.S., Yin B., Coleman R.E., DeGrado T.R., Landolfo C.K., Lowe J.E., Annex B.H. and Landolfo K.P., Therapeutic angiogenesis in chronically ischemic porcine myocardium: comparative effects of bFGF and VEGF. Ann. Thorac. Surg. 77: 812-818, 2004.

3. Rosengart T.K., Lee L.Y., Patel S.R., Sanborn T.A., Parikh M., Bergman G.W., Hachamovitch R., Szulc M., Kligfield P.D., Okin P.M., Hahn R.T., Devereux R.B., Post M.R., Hackett N.R., Foster T., Grasso T.M., Lesser M.L., Isom O.W. and Crystal R.G., Angiogenesis gene therapy: phase I assessment of direct intramyocardial administration of an adenovirus vector expressing VEGF121 cDNA to individuals with clinically significant severe coronary artery disease. Circulation 100: 468-474, 1999.

4. Symes J.F., Losordo D.W., Vale P.R., Lathi K.G., Esakof D.D., Mayskiy M. and Isner J.M., Gene therapy with vascular endothelial growth factor for inoperable coronary artery disease. Ann. Thorac. Surg. 68: 830-836, 1999. Discussion 836-837.

5. Schumacher B., Pecher P., von Specht B.U. and Stegmann $\mathrm{T}$., Induction of neoangiogenesis in ischemic myocardium by human growth factors: first clinical results of a new treatment of coronary heart disease. Circulation 97: 645$650,1998$.

6. Laham R.J., Chronos N.A., Pike M., Leimbach M.E., Udelson J.E., Pearlman J.D., Pettigrew R.I., Whitehouse M.J., Yoshizawa C. and Simons M., Intracoronary basic fibroblast growth factor (FGF-2) in patients with severe ischemic heart disease: results of a phase I open-label dose escalation study. J. Am. Coll. Cardiol. 36: 2132-2139, 2000.

7. Henry T.D., Annex B.H., McKendall G.R., Azrin M.A., Lopez J.J., Giordano F.J., Shah P.K., Willerson J.T., Benza R.L., Berman D.S., Gibson C.M., Bajamonde A., Rundle A.C., Fine J. and McCluskey E.R., The VIVA trial: vascular endothelial growth factor in ischemia for vascular angiogenesis. Circulation 107: 1359-1365, 2003.

8. Simons M., Annex B.H., Laham R.J., Kleiman N., Henry T., Dauerman H., Udelson J.E., Gervino E.V., Pike M., Whitehouse M.J., Moon T. and Chronos N.A., Pharmacological treatment of coronary artery disease with recombinant fibroblast growth factor-2: double-blind, randomized, controlled clinical trial. Circulation 105: 788-793, 2002.

9. Hughes G.C., Post M.J., Simons M. and Annex B.H., Translational physiology: porcine models of human coronary artery disease: implications for preclinical trials of therapeutic angiogenesis. J. Appl. Physiol. 94: 1689-1701, 2003.

10. Biswas S.S., Hughes G.C., Scarborough J.E., Domkowski P.W., Diodato L., Smith M.L., Landolfo C., Lowe J.E., Annex B.H. and Landolfo K.P., Intramyocardial and intracoronary basic fibroblast growth factor in porcine hibernating myocardium: a comparative study. J. Thorac. Cardiovasc. Surg. 127: 34-43, 2004.

11. Horvath K.A., Chiu E., Maun D.C., Lomasney J.W., Greene R., Pearce W.H. and Fullerton D.A., Up-regulation of vascular endothelial growth factor mRNA and angio- genesis after transmyocardial laser revascularization. Ann. Thorac. Surg. 68: 825-829, 1999.

12. Patel S.R., Lee L.Y., Mack C.A., Polce D.R., El-Sawy T., Hackett N.R., Ilercil A., Jones E.C., Hahn R.T., Isom O.W., Rosengart T.K. and Crystal R.G., Safety of direct myocardial administration of an adenovirus vector encoding vascular endothelial growth factor 121. Hum. Gene. Ther. 10: 1331-1348, 1999.

13. Tio R.A., Tkebuchava T., Scheuermann T.H., Lebherz C., Magner M., Kearny M., Esakof D.D., Isner J.M. and Symes J.F., Intramyocardial gene therapy with naked DNA encoding vascular endothelial growth factor improves collateral flow to ischemic myocardium. Hum. Gene. Ther. 10: 2953-2960, 1999.

14. Bernotat-Danielowski S., Sharma H.S., Schott R.J. and Schaper W., Generation and localisation of monoclonal antibodies against fibroblast growth factors in ischaemic collateralised porcine myocardium. Cardiovasc. Res. 27: 1220-1228, 1993.

15. Roth D.M., Maruoka Y., Rogers J., White F.C., Longhurst J.C. and Bloor C.M., Development of coronary collateral circulation in left circumflex Ameroid-occluded swine myocardium. Am. J. Physiol. 253: H1279-H1288, 1987.

16. Roth D.M., White F.C., Nichols M.L., Dobbs S.L., Longhurst J.C. and Bloor C.M., Effect of long-term exercise on regional myocardial function and coronary collateral development after gradual coronary artery occlusion in pigs. Circulation 82: 1778-1789, 1990.

17. Davis S., Aldrich T.H., Jones P.F., Acheson A., Compton D.L., Jain V., Ryan T.E., Bruno J., Radziejewski C., Maisonpierre P.C. and Yancopoulos G.D., Isolation of angiopoietin-1, a ligand for the TIE2 receptor, by secretiontrap expression cloning. Cell 87: 1161-1169, 1996.

18. Valenzuela D.M., Griffiths J.A., Rojas J., Aldrich T.H., Jones P.F., Zhou H., McClain J., Copeland N.G., Gilbert D.J., Jenkins N.A., Huang T., Papadopoulos N., Maisonpierre P.C., Davis S. and Yancopoulos G.D., Angiopoietins 3 and 4: diverging gene counterparts in mice and humans. Proc. Natl Acad. Sci. USA 96: 1904-1909, 1999.

19. Kim I., Kim H.G., Moon S.O., Chae S.W., So J.N., Koh K.N., Ahn B.C. and Koh G.Y., Angiopoietin-1 induces endothelial cell sprouting through the activation of focal adhesion kinase and plasmin secretion. Circ. Res. 86: 952959, 2000.

20. Kim I., Kim H.G., So J.N., Kim J.H., Kwak H.J. and Koh G.Y., Angiopoietin-1 regulates endothelial cell survival through the phosphatidylinositol 3'-kinase/Akt signal transduction pathway. Circ. Res. 86: 24-29, 2000.

21. Audero E., Cascone I., Zanon I., Previtali S.C., Piva R., Schiffer D. and Bussolino F., Expression of angiopoietin-1 in human glioblastomas regulates tumor-induced angiogenesis: in vivo and in vitro studies. Arterioscler. Thromb. Vasc. Biol. 21: 536-541, 2001.

22. Yamauchi A., Ito Y., Morikawa M., Kobune M., Huang J., Sasaki K., Takahashi K., Nakamura K., Dehari H., Niitsu Y., Abe T. and Hamada H., Pre-administration of angiopoietin-1 followed by VEGF induces functional and mature vascular formation in a rabbit ischemic model. J. Gene. Med. 5: 994-1004, 2003.

23. Jones M.K., Kawanaka H., Baatar D., Szabo I.L., Tsugawa K., Pai R., Koh G.Y., Kim I., Sarfeh I.J. and Tarnawski A.S., Gene therapy for gastric ulcers with single 
local injection of naked DNA encoding VEGF and angiopoietin-1. Gastroenterology 121: 1040-1047, 2001.

24. Suri C., Jones P.F., Patan S., Bartunkova S., Maisonpierre P.C., Davis S., Sato T.N. and Yancopoulos G.D., Requisite role of angiopoietin-1, a ligand for the TIE2 receptor, during embryonic angiogenesis. Cell 87: 1171-1180, 1996.

25. Gamble J.R., Drew J., Trezise L., Underwood A., Parsons M., Kasminkas L., Rudge J., Yancopoulos G. and Vadas M.A., Angiopoietin-1 is an antipermeability and antiinflammatory agent in vitro and targets cell junctions. Circ. Res. 87: 603-607, 2000.

26. Wang Y., Pampou S., Fujikawa K. and Varticovski L., Opposing effect of angiopoietin-1 on VEGF-mediated disruption of endothelial cell-cell interactions requires activation of PKC beta. J. Cell. Physiol. 198: 53-61, 2004.

27. Lin M.I. and Sessa W.C., Antiangiogenic therapy: creating a unique "window" of opportunity. Cancer Cell. 6: 529531, 2004.

28. Winkler F., Kozin S.V., Tong R.T., Chae S.S., Booth M.F., Garkavtsev I., Xu L., Hicklin D.J., Fukumura D., di Tomaso E., Munn L.L. and Jain R.K., Kinetics of vascular normalization by VEGFR2 blockade governs brain tumor response to radiation: role of oxygenation, angiopoietin-1, and matrix metalloproteinases. Cancer Cell 6: 553-563, 2004.

29. Shim W.S., Teh M., Bapna A., Kim I., Koh G.Y., Mack P.O. and Ge R., Angiopoietin 1 promotes tumor angiogenesis and tumor vessel plasticity of human cervical cancer in mice. Exp. Cell Res. 279: 299-309, 2002.

30. Ye L., Haider H., Jiang S., Ge R., Law P.K. and Sim E.K., High efficiency transduction of human VEGF165 into human skeletal myoblasts: in vitro studies. Exp. Mol. Med. 35: 412-420, 2003.

31. Ye L., Haider H., Jiang S., Ge R., Law P.K. and Sim E.K., In vitro functional assessment of human skeletal myoblasts after transduction with adenoviral bicistronic vector carrying human VEGF(165) and angiopoietin-1. J. Heart Lung Transplant. 24: 1393-1402, 2005.

32. Mack C.A., Patel S.R., Schwarz E.A., Zanzonico P., Hahn R.T., Ilercil A., Devereux R.B., Goldsmith S.J., Christian T.F., Sanborn T.A., Kovesdi I., Hackett N., Isom O.W., Crystal R.G. and Rosengart T.K., Biologic bypass with the use of adenovirus-mediated gene transfer of the complementary deoxyribonucleic acid for vascular endothelial growth factor 121 improves myocardial perfusion and function in the ischemic porcine heart. J. Thorac. Cardiovasc. Surg. 115: 168-176, 1998Discussion 176-167.

33. Matsunaga T., Warltier D.C., Tessmer J., Weihrauch D., Simons M. and Chilian W.M., Expression of VEGF and angiopoietins- 1 and -2 during ischemia-induced coronary angiogenesis. Am. J. Physiol. Heart Circ. Physiol. 285: H352-H358, 2003.

34. Peirce S.M., Price R.J. and Skalak T.C., Spatial and temporal control of angiogenesis and arterialization using focal applications of VEGF164 and Ang-1. Am. J. Physiol. Heart Circ. Physiol. 286: H918-H925, 2004.

35. Scholz D., Ziegelhoeffer T., Helisch A., Wagner S., Friedrich C., Podzuweit T. and Schaper W., Contribution of arteriogenesis and angiogenesis to postocclusive hindlimb perfusion in mice. J. Mol. Cell Cardiol. 34: 775-787, 2002.

36. Kondoh K., Koyama H., Miyata T., Takato T., Hamada H. and Shigematsu H., Conduction performance of collateral vessels induced by vascular endothelial growth factor or basic fibroblast growth factor. Cardiovasc. Res. 61: 132142, 2004.

37. Lutter G., Quaden R. and Cremer J., Biological bypass in cardiovascular surgery. Thorac. Cardiovasc. Surg. 52: 237248, 2004.

38. Zimmermann R., Arras M., Ullmann C., Strasser R., Sack S., Mollnau H., Schaper J. and Schaper W., Time course of mitosis and collateral growth following coronary microembolization in the porcine heart. Cell Tissue Res. 287: 583-590, 1997.

39. Hariawala M.D., Horowitz J.R., Esakof D., Sheriff D.D., Walter D.H., Keyt B., Isner J.M. and Symes J.F., VEGF improves myocardial blood flow but produces EDRFmediated hypotension in porcine hearts. J. Surg. Res. 63: 77-82, 1996.

40. Chong A.Y., Caine G.J., Freestone B., Blann A.D. and Lip G.Y., Plasma angiopoietin-1, angiopoietin-2, and angiopoietin receptor tie-2 levels in congestive heart failure. J. Am. Coll. Cardiol. 43: 423-428, 2004.

41. Haider H., Ye L., Jiang S., Ge R., Law P.K., Chua T., Wong P. and Sim E.K., Angiomyogenesis for cardiac repair using human myoblasts as carriers of human vascular endothelial growth factor. J. Mol. Med. 82: 539-549, 2004.

42. Takahashi K., Ito Y., Morikawa M., Kobune M., Huang J., Tsukamoto M., Sasaki K., Nakamura K., Dehari H., Ikeda K., Uchida H., Hirai S., Abe T. and Hamada H., Adenoviral-delivered angiopoietin-1 reduces the infarction and attenuates the progression of cardiac dysfunction in the rat model of acute myocardial infarction. Mol. Ther. 8: 584-592, 2003.

43. Siddiqui A.J., Blomberg P., Wardell E., Hellgren I., Eskandarpour M., Islam K.B. and Sylven C., Combination of angiopoietin-1 and vascular endothelial growth factor gene therapy enhances arteriogenesis in the ischemic myocardium. Biochem. Biophys. Res. Commun. 310: 1002-1009, 2003.

44. Gurunluoglu R., Lubiatowski P., Goldman C.K., Carnevale K. and Siemionow M., Enhancement of muscle flap hemodynamics by angiopoietin-1. Ann. Plast. Surg. 48: 401-409, 2002.

45. Chae J.K., Kim I., Lim S.T., Chung M.J., Kim W.H., Kim H.G., Ko J.K. and Koh G.Y., Coadministration of angiopoietin-1 and vascular endothelial growth factor enhances collateral vascularization. Arterioscler. Thromb. Vasc. Biol. 20: 2573-2578, 2000.

46. Hattori K., Dias S., Heissig B., Hackett N.R., Lyden D., Tateno M., Hicklin D.J., Zhu Z., Witte L., Crystal R.G., Moore M.A. and Rafii S., Vascular endothelial growth factor and angiopoietin-1 stimulate postnatal hematopoiesis by recruitment of vasculogenic and hematopoietic stem cells. J. Exp. Med. 193: 1005-1014, 2001.

47. Schaper W., Flameng W., Winkler B., Wusten B., Turschmann W., Neugebauer G., Carl M. and Pasyk S., Quantification of collateral resistance in acute and chronic experimental coronary occlusion in the dog. Circ. Res. 39: 371-377, 1976.

48. Schwarz E.R., Speakman M.T., Patterson M., Hale S.S., Isner J.M., Kedes L.H. and Kloner R.A., Evaluation of the effects of intramyocardial injection of DNA expressing vascular endothelial growth factor (VEGF) in a myocardial infarction model in the rat-angiogenesis and angioma formation. J. Am. Coll. Cardiol. 35: 1323-1330, 2000.

49. Lazarous D.F., Shou M., Stiber J.A., Hodge E., Thirumurti V., Goncalves L. and Unger E.F., Adenoviral-mediated 
gene transfer induces sustained pericardial VEGF expression in dogs: effect on myocardial angiogenesis. Cardiovasc. Res. 44: 294-302, 1999.

50. Masaki I., Yonemitsu Y., Yamashita A., Sata S., Tanii M., Komori K., Nakagawa K., Hou X., Nagai Y., Hasegawa M., Sugimachi K. and Sueishi K., Angiogenic gene therapy for experimental critical limb ischemia: acceleration of limb loss by overexpression of vascular endothelial growth factor 165 but not of fibroblast growth factor-2. Circ. Res. 90: 966-973, 2002.

51. Shyu K.G., Chang H. and Isner J.M., Synergistic effect of angiopoietin-1 and vascular endothelial growth factor on neoangiogenesis in hypercholesterolemic rabbit model with acute hindlimb ischemia. Life Sci. 73: 563-579, 2003.
52. Zhou Y.F., Stabile E., Walker J., Shou M., Baffour R., Yu Z., Rott D., Yancopoulos G.D., Rudge J.S. and Epstein S.E., Effects of gene delivery on collateral development in chronic hypoperfusion: diverse effects of angiopoietin-1 versus vascular endothelial growth factor. J. Am. Coll. Cardiol. 44: 897-903, 2004.

53. Drake C.J. and Little C.D., Exogenous vascular endothelial growth factor induces malformed and hyperfused vessels during embryonic neovascularization. Proc. Natl Acad. Sci. USA 92: 7657-7661, 1995.

54. Ozawa C.R., Banfi A., Glazer N.L., Thurston G., Springer M.L., Kraft P.E., McDonald D.M. and Blau H.M., Microenvironmental VEGF concentration, not total dose, determines a threshold between normal and aberrant angiogenesis. J. Clin. Invest. 113: 516-527, 2004. 